\title{
Polyneuropathy, Myocardial Dysfunction and Pericardial Effusion Following Duodenal Switch
}

\author{
Meir Mouallem*, Moran Livne Margolin, Yehudit Eden Friedman, Hadas Blankenfeld
}

\section{ABSTRACT}

Duodenal Switch procedure is a type of bariatric surgery that was reserved for severely morbid obese people. Patients undergoing this procedure are at high risk for nutrient deficiencies. In this report we present a case of a patient who had developed polyneuropathy, generalized muscle weakness, Wernicke encephalopathy, myocardial dysfunction and pericardial effusion six years following this operation. He was treated by multivitamins and trace elements with a complete resolution of all of these disturbances. The patient was fully rehabilitated.

\section{KEYWORDS}

bariatric surgery; myocardial dysfunction; pericardial effusion; polyneuropathy

\section{AUTHOR AFFILIATIONS}

Department of Medicine E, Sheba Medical Center, Tel-Hashomer affiliated to Sackler Faculty of Medicine, Tel Aviv University, Israel * Corresponding author: Department of Medicine E, Sheba Medical Center, Tel-Hashomer 52621, Israel; e-mail: mouallem@post.tau.ac.il

Received: 25 December 2017

Accepted: 9 July 2018

Published online: 12 December 2018

Acta Medica (Hradec Králové) 2018; 61(3): 111-113

https://doi.org/10.14712/18059694.2018.128

(C) 2018 The Authors. This is an open-access article distributed under the terms of the Creative Commons Attribution License (http://creativecommons.org/licenses/by/4.0), which permits unrestricted use, distribution, and reproduction in any medium, provided the original author and source are credited. 


\section{INTRODUCTION}

The rate of obesity continues to rise worldwide and is considered a major healthcare burden (1). Bariatric surgeries offer an effective treatment modality for this epidemic due to their dramatic and durable results. Bariatric surgeries are classified into three categories: Restrictive, malabsorptive, and restrictive-malabsorptive, which combines both types of procedures (2). However, these procedures have been associated with increased risk of nutritional deficiencies. Reported neurological pathologies that are related to nutritional deficiencies are variable and include encephalopathy, optic neuropathy, myelopathy, polyradiculoneuropathy, and polyneuropathy (3). Cardiac dysfunction and pericardial disease secondary to severe weight loss are not mentioned. In this report we present a patient that developed severe neurological damage, cardiac dysfunction and pericardial effusion following a bariatric surgery and recurrent vomiting.

\section{CASE REPORT}

A 42 year's old male patient suffered from severe obesity since childhood. Concurrently, he developed a binge eating disorder with forced vomiting. Six years ago as his weight reached $180 \mathrm{~kg}$ and his BMI was 53.2, he was referred to bariatric consultation and underwent partial gastrectomy with Roux-en-Y gastroenterostomy with biliopancreatic diversion. During the following years he lost $100 \mathrm{~kg}$ but continued to vomit. Additionally, he did not adhere to the recommended supplementation of essential vitamins and trace elements.

On November 2016 the patient was admitted due to progressive muscle weakness and walking disturbances. EMG demonstrated axonal neuropathy and lumbar puncture was performed with normal level of protein and without pleocytosis. He was diagnosed with atypical Guillain Barre Syndrome (GB Syndrome) and received IVIG treatment. He was then sent to a rehabilitation center where he was treated with vitamins and trace elements which resulted in clinical improvement. Two months later he was readmitted due to diplopia and vertigo. Physical examination demonstrated nystagmus. MRI of the brain was normal and he was sent home. On June 2017 he was referred to our hospital due to chest pain, confusion, blurred vision and leg weakness. On admission he was confused and non-cooperative. His blood pressure was $80 / 50 \mathrm{mmHg}$, and pulse rate was 100 and regular. Physical examination revealed elevated jugular venous pressure. On his neurological examination, a prominent horizontal nystagmus with an abduction paralysis of both eyes, and muscle weakness with hyporeflexia was observed. The ECG demonstrated low voltage and inversion of the T waves with ST depression in the anterior wall. An Echocardiogram demonstrated a moderate pericardial effusion with diffuse global left ventricular dysfunction. Coronary CT scan was normal without evidence of ischemia. EMG showed axonal neuropathy. Results of the lumbar puncture were normal.
His laboratory results showed slight pancytopenia and decreased levels of copper, ceruloplasmin, vitamin A and $\mathrm{D}$ and B1. Additionally, his troponin level was elevated (Table 1). Liver function tests, Prothrombin time and thyroid functions were all normal.The patient was treated with multivitamins and trace elements intravenously and with Selenium and vitamin D.

Tab. 1 Laboratory results of the patient at admission (normal level in parentheses).

\begin{tabular}{|l|l|}
\hline Leukocytes (4000-10800) & 6040 \\
\hline Hemoglobin $(13.5-17.7 \mathrm{~g} / \mathrm{dL})$ & 10.2 \\
\hline Platelets $(130-440000)$ & 119000 \\
\hline Thiamine $(66.5-200 \mathrm{nmol} / \mathrm{L})$ & 46.2 \\
\hline Vitamin A $(0.3-0.7 \mathrm{mg} / \mathrm{dL})$ & 0.2 \\
\hline Copper $(50-150 \mathrm{micgr} / \mathrm{dL})$ & 42 \\
\hline Ceruloplasmin $(20-60 \mathrm{mg} / \mathrm{dL})$ & 10.2 \\
\hline Calcium $(8.1-10.4 \mathrm{mg} / \mathrm{dL})$ & 8.4 \\
\hline $250 H$ Vitamin D $(\mathrm{deficiency}<10 \mathrm{ng} / \mathrm{ml})$ & 5.1 \\
\hline Cholesterol $(130-200 \mathrm{mg} / \mathrm{dL})$ & 76 \\
\hline Troponin $(<0.07 \mathrm{micg} / \mathrm{l})$ & 1.05 \\
\hline Albumin $(3.6-5.5 \mathrm{~g} / \mathrm{l})$ & 2.9 \\
\hline CRP $(0-5 \mathrm{mg} / \mathrm{dL})$ & 0.57 \\
\hline Iron $(60-170 \mathrm{micg} / \mathrm{dL})$ & 37 \\
\hline Lactate $(6-18 \mathrm{md} / \mathrm{dL})$ & 46 \\
\hline
\end{tabular}

CRP - C Reactive Protein

We noticed a dramatic improvement, and after two weeks of treatment the blurred vision disappeared and the eye movements returned to normal. Muscle weakness improved substantially. Nystagmus was the last sign to disappear. Cardiac global function normalized and there was minimal residual pericardial effusion. The ECG changes disappeared as well, with normalization of the QRS voltage and correction of the ST-T changes (Figure 1-2). The patient was discharged with a recommendation to maintain a healthy diet enriched with vitamins, trace elements, copper and selenium.

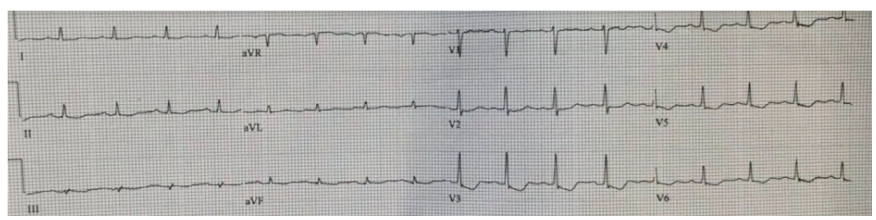

Admission

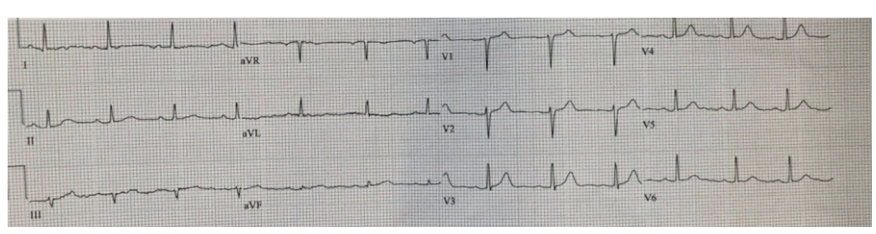

Discharge

Fig. 1 ECG on admission and discharge. 

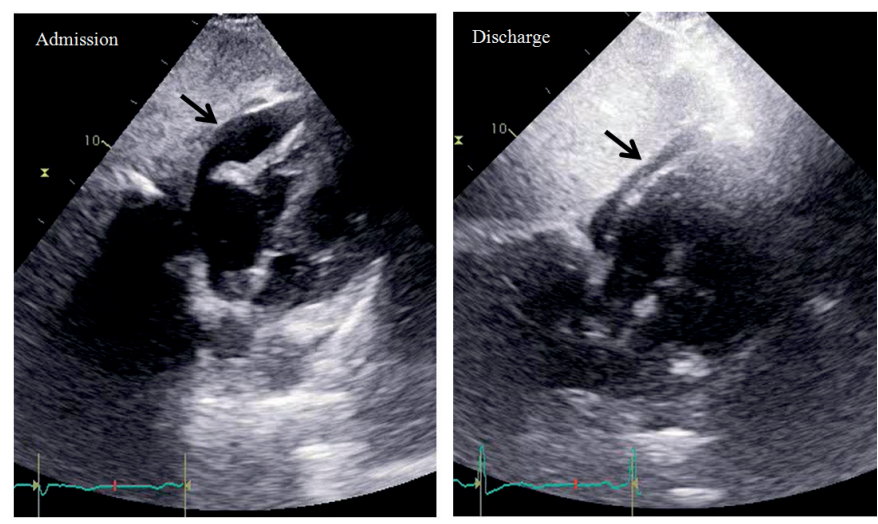

Fig. 2 Echocardiogram on admission and discharge.

The arrow signs the pericardial effusion.

\section{DISCUSSION}

Biliopancreatic diversion is an effective procedure leading to durable weight loss. It not only achieves a considerable weight loss, but has a high success rate in maintaining weight thereafter. The relatively low number of patients undergoing this procedure reflects its surgical complexity and the fear from secondary nutritional deficiencies and associated adverse effects (4).

Neurological complications following bariatric surgery can develop within a few weeks to many years afterwards (3). These complications may result from mechanical or inflammatory mechanisms but mainly from nutritional deficiencies. Rapidly progressive polyradiculoneuropathy resembling GB Syndrome has been associated with vitamin B1 deficiency (5). Other neurological complications of bariatric surgeries include Wernicke's encephalopathy, optic neuropathy, myelopathy, peripheral neuropathy and myopathy.

Another interesting and less familiar finding was pancytopenia. Copper deficiency may be the cause of this disturbance (6), and probably also contributed to some of the neurological damage. Surprisingly, ceruloplasmin level was also reduced, perhaps explained by underproduction by the liver as a response to the low copper levels.

The most interesting disturbances were pericardial effusion and cardiac dysfunction. There was no evidence of viral or inflammatory pericarditis. Pericardial effusion is described in patients suffering from anorexia nervosa (7). The pathophysiology for the development of pericardial effusion is not known, however the effusion usually remits by a concurrent increase in weight. Cardiac dysfunction and the ECG changes were difficult to explain. Coronary artery disease was excluded by normal coronary artery CT. No description of patients demonstrating such changes following weight loss or malnutrition was found in recent literature. High output cardiac failure is the classical feature of patients with cardiovascular Beri-Beri, although thiamine deficiency can rarely cause low cardiac output (8), as was the presentation of our patient. Selenium deficiency can cause dilated cardiomyopathy, a condition that was not compatible with the echocardiogram of the patient. An article published in the Br Heart J on 1951, described 30 patients suffering from malnutrition and heart disease that was not compatible with Beri-Beri (9). It is clear that at that time it was impossible to measure levels of vitamins and trace elements. The electrocardiograms that were performed, demonstrated inverted $\mathrm{T}$ waves in the anterior wall, compatible with the ECG changes in our patient. As with our patient, these changes normalized when the nutritional disorder was corrected. Our patient's cardiac damage is not fully understood. We suspect that combined deficiency of thiamine, selenium and copper contributed to this disorder. Copper deficiency in animals can induce enlargement of the heart and congestive heart failure (10). It is important to note that in patients with Anorexia Nervosa myocardial fibrosis was found in $23 \%$ of the patients that were evaluated by cardiac magnetic resonance imaging (7). Reduced left ventricular mass was also very common.

\section{CONCLUSION}

Neurological disturbances can appear following bariatric surgeries. Myocardial dysfunction and pericardial effusion were not described previously. The correction of the nutritional deficiencies resulted in resolution of all the symptoms.

\section{REFERENCES}

1. Ogden CL, Carrol MD, Kit BK. Prevalence of childhood and adult obesity in the United-States, 2011-2012. JAMA 2014; 311: 806-14.

2. Smith BR, Schauer P, Nguyen NT. Surgical approaches to the treatment of obesity: bariatric surgery. Endocrinol Metab Clin North Am 2008; 37: 943-64.

3. Landais A. Neurological complications of bariatric surgery. Obes Surg 2014; 24: 1800-7.

4. Topart P, Becouarn G, Delarue J. Weight loss and nutritional outcomes 10 years after biliopancreatic diversion with duodenal switch. Obes Surg 2017; 7: 1645-50.

5. Koffman BM, Greenfield LJ, ALI II, Pirzada NA. Neurologic complications after surgery for obesity. Muscle Nerve 2006; 33: 166-76.

6. Btaiche IF, Yeh AY, Wu IJ, Khalidi N. Neurologic dysfunction and pancytopenia secondary to acquired copper deficiency following duodenal switch: case report and review of the literature. Nutr Clin Pract 2011; 26: 583-92.

7. Oflaz S, Yucel B, Oz F, et al. Assessment of myocardial damage by cardiac MRI in patients with anorexia nervosa. Int J Eat Disord 2013; 46: 862-66.

8. McIntyre N, Stanley NN. Cardiac beriberi: two modes of presentation. Br Med J 1971; 3(5774): 567-9.

9. Gillanders AD. Nutritional heart disease. Br Heart J 1951; 13: 177-96.

10. Elsherif L, Ortines RV, Saari JT, Kang YJ. Congestive heart failure in copper-deficient mice. Exp Biol Med 2003; 228: 811-7. 